Article

\title{
Sustaining Upgrading in Agricultural Value Chains? State-Led Value Chain Interventions and Emerging Bifurcation of the South Indian Smallholder Tea Sector
}

\author{
Marianne Nylandsted Larsen \\ Department of Geosciences and Nature Resource Management, University of Copenhagen, \\ 1350 Copenhagen K, Denmark; mnl@ign.ku.dk; Tel.: +45-35-32-25-00 \\ Academic Editor: Hossein Azadi \\ Received: 16 August 2016; Accepted: 25 October 2016; Published: 28 October 2016
}

\begin{abstract}
The Global Value Chain (GVC) approach has emerged as a novel methodological device for analysing economic globalization and international trade. The suitability of the chain metaphor and strategies for moving up the ladder of GVCs ("upgrade") is widely echoed in international development agencies and public agencies in the Global South. Most of the existing GVC studies focus on new forms of firm-to-firm relationships and the role of lead firms and chain governance in defining upgrading opportunities. This paper examines the role of the state and local institutional initiatives in promoting upgrading in agricultural GVCs originating in rural areas of the Global South. The paper draws on research conducted in the South Indian smallholder tea sector. The paper argues that successful forms of state-led chain interventions not only contribute to upgrading of the smallholder-brought leaf factory strand of the GVC originating in the South Indian tea sector, but might also result in increasing bifurcation of smallholders integrated into high-margin markets through prominent bought leaf factories and a mass of "others" outside this tightly coordinated strand of the tea value chain.
\end{abstract}

Keywords: global value chains; state-led interventions; upgrading; bifurcation; inclusive development strategies; smallholder tea; horizontal and vertical coordination; South India

\section{Introduction}

Since the early 2000s, the Global Value Chain (GVC) approach has proliferated as a novel methodological device for analysing economic globalization and international trade [1-4]. GVC studies focus on the emergence of new global production systems in which economic integration goes beyond international trade in raw materials and final products to include the internationally dispersed but centrally coordinated production of given commodities or manufactured products by "chains" of independent economic actors [5]. The appearance of these systems is related to the international extension and externalisation of manufacturing activities previously internalised "within the organisational boundaries of vertically integrated corporations" [6] (p. 7). As Gereffi emphasizes, we see "large firms in globalized production systems simultaneously participate in many different countries, not in an isolated or segmented fashion but as part of their global production and distribution strategies" [5] (p. 96). Therefore, the geographical spread of transnational production arrangements, their organisational scope, or, in other words, linkages between various economic agents-raw-material suppliers, factories, trader and retailers-become pertinent in order to understand their overall dynamics as well as their sources of stability and change [7].

Most of the existing GVC studies focus on new forms of firm-to-firm relationships and the role of lead firms-conceptualised as companies holding a position in the chain that allows them to determine 
the operational and functional scope of other chain participants-and chain governance in defining upgrading opportunities [8,9]. A key argument underlying these studies is that mechanisms and circumstances for upgrading possibilities and patterns for inclusion and exclusion should mainly be sought within the value chain [2] (pp. 28-29). Public regulation and the wide institutional framework as a conditional factor for GVC governance and upgrading are rarely studied, though a notable recent study on the nature and scope of institutional support for upgrading processes is provided by Neilson and Pritchard (2009) [10]. The authors comprehend governance arrangements and institutional formations as being co-produced by internal, place-bound actors and external "lead firm" actors [11] (p. 43) and stress that "prospects for upgrading hinge on how the multi-scalar industrial formations into which economic actors are embedded interact with new governance arrangements frequently set in train by agents remote from their immediate environment" [10] (p. 211).

The chain metaphor and strategies for gaining access to and upgrade within GVC have been echoed and adopted by almost all major multilateral donor agencies during the last decade (for a comprehensive review of strategy papers published by international development agencies with a value chain focus, see $[1,2,12])$. Value chain intervention strategies have also proliferated amongst state agencies as part of a new (post-Washington Consensus) generation of policies addressing the role of the state in mediating development strategies [12]. Although, for obvious reasons, there are huge variations and differences in the adaptation of value chain inspired development projects implemented by agencies ranging from non-governmental organisations, to multilateral donor organisations and agencies (see also [2,12]), the adaptation of upgrading is based on an implicit perception that it mainly results from internal chain-specific dynamics (firm-to-firm relationships). Once entry is gained by producers in developing countries, learning effects take place within GVCs arising from firm-to-firm relationships. The prevailing narrative stresses competition and the free market as desirable for the welfare of producers in the Global South, and lead firms or groups of actors downstream in the chain are mitigating information asymmetry through the dynamics of inter-firm/farm coordination, while the state appears as a "market-facilitating" institution [1] (p. 1240).

The research questions which drive this paper is the role of the state and local institutional initiatives in promoting upgrading in agricultural GVCs originating in rural areas of the Global South, and the limitations to state-led upgrading of agricultural GVCs in the contemporary global economy. In order to answer these questions, the paper draws on fieldwork conducted in the GVC for tea originating in the smallholder-bought leaf factory strand of the tea chain in South India. In the case of the GVC for tea, leading branded tea manufacturers have conquered a substantial share of trade in tea, and proprietary brands dominate most consumer markets in the Global North [10]. Just seven companies are estimated to account for 90 per cent of tea traded into European and North American consumer markets, while four leading branded manufacturers-Unilever, Van Rees, James Finlay and Tata Tetley-are estimated to dominate tea trade [13]. Branded tea manufacturers have strategically diversified from direct tea cultivation and outsourced (part of) their production and processing capacity as part of their focus on core competences downstream in the chain, notably branding, packaging and marketing. This restructuring of their supply chains provided "room for manoeuvre" for smallholder production and prospects for upgrading as the branded tea manufacturers increasingly source deliveries directly from producers (smallholders, tea estates and blending companies). Besides the operational shifts in the activities of the leading tea manufacturers, they seek to stimulate demand and/or defend their market position through brand development, product innovation and market segmentation. Smallholder tea production is typically targeted by branded tea manufacturers as a means to secure the reputation of their brands and demonstrate that certain basic principles concerning ethical and environmental impacts of production and processing are addressed in their supply chain. For example, the world's largest buyer of black tea-Unilever-only purchases Rainforest Alliance certified tea for its two major brands, Lipton and PG Tips. Apart from certification of its own plantations, Unilever increasingly sources tea from smallholders and engages in programmes on 
smallholder compliance with Rainforest Alliance certification, for example in Kenya (for more details see [14-16]).

Branded tea manufacturers such as Unilever and Tata Tetley are present in the South Indian tea landscape and coexist with the smallholder-bought leaf factory strand of the chain. The tea estate and smallholder-bought leaf factory sub-sectors have followed a largely independent path during the last decades and no significant relationships have emerged between the two sub-sectors of the South Indian tea industry. Following a collapse in tea prices in the late 1990s, which had serious repercussions for smallholders and bought leaf factories (hereafter BLFs) in South India, the Tea Board of India launched a comprehensive "Quality Upgrading" programme early in the new millennium. This paper argues that value chain interventions by the state (through the Tea Board of India) has been pivotal in product and process upgrading in the smallholder-BLF strand of the value chain, which additionally has facilitated functional upgrading by some BLF. Vertical linkages and improved manufacturing practices have a positive effect on BLF performance, which is rewarded at auction centres and increasing also through direct linkages to blending companies, and transmitted to the smallholder level in form of higher prices attached to higher quality tea leaves. Higher quality standards and vertical coordination, however, seem to result in increasing bifurcation where some smallholder growers are integrated into high-margin markets through successful upgrading strategies by prominent BLFs and a mass of "others" locked into thinner and volatile markets.

The article is accordingly organised into seven sections. Following the Introduction, the Section 2 engages with the current conceptual debates on upgrading in global agricultural value chains. The paper maintains that a tangible way to analyse the elusive question of how producers, regions and/or countries scale the value-added ladder, or in other words upgrade in the era of globalization is to adopt a value chain specific approach. The concept of upgrading provided by the seminal work of Humphrey and Schmitz (2002) and recent studies on the nature and scope of institutional support for upgrading is elaborated $[8,10]$. Section 3 outlines the entry point and methods used in researching the GVC for tea and in particular the "touchdown" and the ramification in the main tea growing area in South India. Sections 4-6 move on to the South Indian context and present and discuss the results. Firstly, a brief outline of the historical development of the tea sector is provided, followed by recent state-governed efforts to upgrade smallholders and BLFs in the South Indian tea sector (Section 4). Section 5 analyses upgrading trajectories at the BLF level. The BLFs manufacture so-called made tea based on either CTC (cut, tea and curl) or orthodox processing methods, where leaves are rolled against a cutting table. The analysis of upgrading takes point of departure in product differentiation at the BLF level as an indicator of upgrading and attempts to discern patterns of differences in the BLFs' strategies related to process, product, and functional upgrading. The analysis shows an merging bifurcation between a group of BLFs that have improved manufacturing practices and started operating in line with the tightly coordinated smallholder-BLF model initiated by the Tea Board of India, and a group of BLFs with a loosely coordinated value chain and main emphasize on increasing volume of one (substandard) "tea quality". Section 6 discusses the limits of state-led upgrading interventions targeting all BLFs in the region, while Section 7 concludes the paper.

\section{Conceptualising Upgrading in Global Agricultural Value Chains}

A GVC is conceptualised as a series of strands or "filaments" (i.e., firm- or country-specific sub-chains) linking producers and enterprises in, for example, developing countries to those in developed ones and a value chain can be seen as "a set of inter-organisational networks clustered around one commodity or product, in which networks are situationally specific, socially constructed and locally integrated" [6] (p. 2). A GVC is constituted by four elements: (1) the input-output structure: a set of products and services linked together in a sequence of value-adding economic activities; (2) the geographical coverage of value chains: the spatial dispersion or concentration of production and distribution networks, comprised of enterprises of different sixes and types; (3) chain governance structures; and (4) public and private institutions at different spatial scales which shape 
the actors and their relationships in the GVC (see Neilson and Pritchard [10] for a solid discussion of the interrelationship between governance and the institutional framework. Apart from the more descriptive aspects of the analytical dimensions-the input-output structure and territoriality-the twin concepts of "governance" and "upgrading" in the GVC approach have received the most attention so far, since this is where the key notions of entry barriers, chain coordination and upgrading possibilities are introduced. The term governance draws attention to the vertical coordination of economic activities through non-market relationships (i.e., inter-firm linkages). Conceptualising governance as "authority and power relations that determine how financial, material and human resources are allocated and flow within a chain" [5] (p. 97) hinges not only on the power of lead firms but also on how coordination in GVCs is exercised through the enforcement of for example higher standards of quality and reliability in produce flow, resulting in reduced risk and investment costs. The concept of upgrading draws attention to the mechanisms by which farms and firms are able to move from low-value to relatively high-value activities through participation in GVCs. Here, the GVC literature discusses how subordinate participation in a GVC may provide indirect access for small producers to markets, technologies and knowledge at lower costs than they would otherwise face. On this basis, GVCs are seen as constituting the organisational basis of participating in international trade and the starting point for attempts by farms and firms in, for example, developing countries to improve their position within it (by making better products more efficiently and with more skilled workers), or in other words to upgrade [17]. The latter is perceived as the process by which producers, regions and/or countries scale the value-added ladder, either by moving to more rewarding functional positions within GVCs, or by making more value-added products.

In the seminal work of Humphrey and Schmitz (2002) [8], upgrading is further deconstructed as:

- process upgrading (inputs are transformed more efficiently by organisational or technical improvements);

- product upgrading (production is moved into more sophisticated product lines, measured by e.g., increased unit values);

- functional upgrading (new functions are acquired, leading to the increased skill content of activities); and

- inter-sectoral upgrading (new productive activities are entered into by clusters of firms).

Humphrey and Schmitz (2002) emphasized that distinct types of upgrading in a particular GVC are dependent on the nature of the relationships that exist between the main actors involved in a transaction, and "different forms of chain governance have different upgrading implications" [8] (p. 1023). The incentives for lead firms to facilitate upgrading of suppliers beyond process and product upgrading (e.g., functional upgrading) require that the lead firms governing the chain "are willing to relinquish" lower value-added functions up- and/or downstream of the chain [8] (p. 1024), which-due to the companies' competitive strategies-is often not the case. Further, as pointed out by Gereffi (2014) [2] and Werner et al. (2014) [1], lead firms might reproduce entry barriers in order to defend their position in the chain, and the extent to which state and development agencies can facilitate programmes to engage smallholder or firm upgrading seems to be more successful if lead firms are facing supply shortages [2] or perceive it as a means to access "large, emerging markets in supplier countries" [1] (p. 1241).

In the recent literature on global agricultural value chains, upgrading has mainly, but not exclusively (see e.g., [18,19]), been analysed through the lens of Humphrey and Schmitz (2002), i.e., product, process, functional upgrading and inter-sectoral upgrading, though the categories have been criticised on several points [20] (For example Ponte and Ewert (2009) [20] analyse upgrading trajectories in the South African wine industry through the categories put forward by Humphrey and Schmitz (2002) [8]. These categories, however, are criticised on several points, notably with regard to the problems of placing various real processes unambiguously in one or the other category (e.g., should complying with food safety standards be classified as product or process 
upgrading?). Ponte and Ewert (2009) suggest a more detailed understanding of upgrading possibilities in agro-food GVCs, including processes usually considered to be downgrading in the GVC literature, e.g., selling lower value products on a larger scale [20].) Several agri-food GVC studies discuss how lead firms facilitate or restrict the prospects for upgrading farms and companies in the Global South (e.g., [9,21-24]). Upgrading potential and limitations for smallholders and agri-food processors as a result of more demanding food safety and quality standards imposed by northern retailers have been studied extensively in Kenya (see amongst others [9,25-27]). Product and process parameters (e.g., GlobalGAP) imposed by northern retailers force exporters and producers in southern countries to acquire a range of new capabilities to retain their relationships. On the one hand, higher performance levels and/or requirements for more functional capacity mean that suppliers need to obtain economies of scale and acquire greater financial resources to carry overheads for additional service provision. This increases entry barriers to smaller and more poorly resourced companies and smallholder cooperatives. Smallholder involvement in the export sector has declined significantly following European retailers' requirement that exports meet the GlobalGAP standards, and production for the retailers' supply chain of fresh fruit and vegetables is now mainly carried out by large contract farms linked to large-scale export companies, while the few smallholders that remain engaged in this supply chain are linked to growers/exporters in various forms of outgrower schemes [26,27].

A key argument underlying these studies is that opportunities for upgrading and entry barriers for smallholders and processors in high-margin markets are increasingly influenced by the strategic needs of a handful of leading retailers or branded manufacturers in the north. Lee et al. (2010) [3] (p. 6) focus on the importance of lead firms' strategies and upgrading opportunities in agri-food GVCs and suggest the prevalence of four distinct agri-food GVC structures, based on the degree of concentration in food production (farmers and manufacturers) and in food retail (supermarkets and other food retailers): buyer-driven retail chains, producer-driven chains, bilateral oligopolies, and traditional markets. According to the authors "each type of value chain structure is associated with a distinctive constellation of food safety and quality standards reflecting the attributes of its lead firms" and smallholder involvement and upgrading potential therefore critically depend on the type of GVC in which they are engaged. In buyer-driven retail chains, such as the GVC for fresh food and vegetables, significant upgrading opportunities for smallholders exist, despite retailers' concern with product safety and quality along the GVC. Typically, these chains are relatively short and exporters in developing countries have incentives to support smallholder production. In contrast, smallholder opportunities for upgrading are likely to be limited in bilateral oligopolies, such as fruit products (bananas and pineapples), and producer-driven chains (coffee and cocoa). In bilateral oligopolies, smallholder involvement and upgrading opportunities relate to participation in contract farming schemes with rather high entry barriers. In producer-driven chains, lead firms (branded manufacturers) are more concerned with quality-based competition and product differentiation than food safety, and relatively to the buyer-driven retail chain, smallholders' upgrading potentials are limited in producer-driven chains because of the presence of large processors in the chain (cocoa grinders and coffee roasters). Traditional markets found in many smallholder-based agro-food chains (such as fresh produce) have lower entry barriers, but upgrading possibilities are limited partly due to a lack of adequate (public and private) support for upgrading [3]. The role of public and private supporting institutions such as extension and training centres, research institutions, and farmer organisations for promoting upgrading are touch upon in relation to traditional markets, but mechanisms for upgrading and barriers should mainly be sought within the chain and upgrading trajectories for smallholders, and local companies are intermediated through their ties with global lead firms [12] (p. 2).

To a large extent, the adaptation of upgrading and value chain inspired development projects implemented by multilateral donor organisations and state agencies is based on this implicit perception: upgrading mainly results from internal chain-specific dynamics and a distinct "life history" of stages or that it can take forms that can be defined in the abstract for value chains in general. Once entry is gained by producers in developing countries, learning effects take place within GVCs arising from 
lead firm-supplier interactions (see also $[2,12]$ ). While value chain linkages embody the capacity for supply chain management and upgrading, the crucial role of institutional support is stressed by Neilson and Pritchard (2009) in their take on upgrading [10]. The authors examine upgrading in the coffee and tea industry in South India, also taking point of departure in the seminal work of Humphrey and Schmitz (2002) [8]. The market dominance of branded tea and coffee manufacturers provides them with great leverage to reshape the functional division of labour along the GVCs for tea, and their purchasing practices strongly influence both price movements and the demand for certain qualities of the products in producing countries-and increasingly also the prospects for smallholder upgrading through the incorporation of producers in this strand of the GVC. These restructuring processes, however, do not occur within a "passive political landscape" as the institutional environment in the tea and coffee sectors in South India shape producers' capacity to participate in GVCs and the economic benefits they obtain from such participation. As stressed by Neilson et al. (2006) [28] (pp. 331-332), the South Indian tea sector "illustrates the crucial role of institutions as arenas for quality upgrading and strategic response formation" and further, "the diligent response by UPASI, KVK and the Tea Board underline how institutions can develop and deploy new strategies for otherwise imperilled smallholders". The same focus on the importance of the role of institutions in upgrading processes is found in Selwyn's (2008) study on the export dependent horticultural value chain in Brazil [19]. Selwyn (2008) emphasize that public institutions such as marketing boards, research and technical service centres, and producer organisations might be the key drivers for upgrading processes as "They can assist potential supplier first to (a) gain access to global markets and (b) maintain their position in them" [19] (p. 391).

The following analysis of upgrading processes in the smallholder-BLF strand of tea chain in South India applies the concept of upgrading provided by Humphrey and Schmitz [8]. The analysis moves beyond the frontier of the "lead firm" in the global tea value chain (i.e., branded tea manufacturers) and explores the role of the state in supporting product, process, and functional upgrading at the BLFs level. Hence, the paper contributes to the writings discussed above by investigating the role of public policy and institutional support on value chain upgrading strategies, but it aims to take the discussion regarding upgrading processes further by suggesting that successful forms of state-led chain interventions not only contribute to upgrading of the strand of the GVC originating in the Global South, but might also result in increasing bifurcation of smallholders integrated into high-margin markets through prominent BLFs and a mass of "others" outside this tightly coordinated strand of the tea value chain.

\section{Materials and Methods}

To explore upgrading processes in the export dependent strand of the GVC for tea in South India, and the role of the state in supporting upgrading, semi-structured interviews were conducted with three main groups of actors in the value chain: Blending companies, BLFs, and tea growers (smallholders and tea estates). The interview guides were structured around a predefined range of issues and aimed at operationalising these in relation to the behaviour of specific groups of subjects. Each interview guide focused on: (1) specific questions related to the actors' (different) role in the tea chain; (2) the horizontal and vertical relationships between actors in the chain; and (3) common themes, notwithstanding actors' different positions in the chain. The interview guide for owners/managers of BLFs included: (1) background to entering the sector and basic data about the BLF; (2) sourcing strategies, competition and pricing, including organisation of buying networks, buying strategies and coverage, forms of quality control and scope of the relationship to smallholders; (3) relationship between the BLF and other BLFs (whether they collaborate or coordinate certain issues), how and why (not); and (4) relationship between the BLF and state agencies and other institutions including supervision and training by the agricultural extension agency. The interview guide for owners/managers of blending companies included: (1) background to entering the sector and basic data about the blending company; (2) export destinations, quality requirements their tea 
product exports must meet; (3) relations between blending companies and importers (e.g., types of contract) as well as the scope of the relationship; and (4) sourcing strategies including relationships between blending companies and leaf manufacturers (BLFs or estates) and/or sourcing strategies at the auctions. The interview guide for tea growers (smallholders and estates) included: (1) background to entering the sector and basic data about the estate/farm household; (2) husbandry and harvest (plucking) practices including range and extent of extension services, grading and quality control procedures; and (3) relationship between tea grower and buyers (e.g., BLF; buying post operators; blenders or importers in the case of tea estates).

In order to obtain a thorough understanding of the type(s) and range of relationships prevailing in the various parts of the chain, similar sets of questions were developed for both "sides" of the relationship, for example between BLFs and tea growers. In addition, in order to compare and contrast different sources of findings addressing the same phenomenon or common themes (for example, issues of quality), all actors were asked similar questions on the subjects. The interviews contained a mixture of open and closed, as well as quantitative and qualitative questions. Using both open and closed questions implied responses that were both straight answers to direct questions and responses characterised by elaborations and opinions. Open questions were particularly suitable for understanding relational aspects between different actors in the chain, both horizontally and vertically, and the underlying processes influencing upgrading trajectories, while closed questions created a base for constructing comparative patterns from individual cases within the different nodes, for example, the number of smallholders supplying tea leaves to BLFs, BLFs processing capacity and possession of land for tea cultivation.

The research covered interviews with private blending companies. Twenty private blending companies were identified and efforts were made to interview them all, but only 13 were interviewed, on the basis of their availability. These companies export tea from South India to markets in Europe, the US, West Asia, the Middle East, Africa and the Commonwealth of Independent States (hereafter CIS). In addition, interviews were held with seven large corporate tea estates exporting mainly to countries in Europe. Interviews were conducted with 22 BLFs. Since the BLFs are dispersed over a huge geographical area in the Nilgiris, specific geographical areas had to be selected. The initial selection of taluks (the administrative unit below district level) and villages was based on degree of competition between BLFs, where the number of BLFs was used as a proxy for higher(er) or low(er) levels of buying competition. This selection criterion is based on the assumption that high or low competition might act as proxies for the greater or lesser involvement of BLFs in smallholder tea production. In addition, the selection of BLFs (and smallholders) in geographical areas was designed to cover a cross-sample of agro-ecological conditions. Within the areas identified, BLFs were selected according to size of factory (production capacity, market share, and sales level). A survey of 110 smallholders were conducted based on their marketing channel and stratified by size of landholding. It was assumed that ownership-related assets (e.g., possession of land, and labour) influence smallholders' ability to comply with more demanding quality requirements, as well as their ability to become engaged in direct sale arrangements with the BLF. Smallholders were selected according to their marketing channel, that is, farmers selling their produce directly to the BLF (or via so-called self-help groups) or to buying agents. Finally, the role of public and private sector initiatives in promoting and upgrading the smallholder-BLF strand of the value chain was elucidated by addressing these topics to respondents in the different segments of the chain (i.e., exporters, blenders, BLFs, smallholders). In addition, interviews were held with brokers and professional tea-testers at the three auction centres in South India-Coonoor, Coimbatore (Tamil Nadu) and Cochin (Kerala)—and in Kolkata (West Bengal) and with various industry representatives including government staff at the Tea Board in Coonoor and Kolkata, the Tea Research Institute, the National Tea Research Foundation, the Indian Tea Association and associations representing tea estates, BLFs and smallholders.

The analysis and interpretation of these data entailed a detailed examination of patterns and explanatory factors, first at each node of the chain, and secondly through an examination of the nature 
and range of the relationships between actors at different nodes in the chain. The remainder of this paper builds on the fieldwork outlined here, though the main focus is on the results from the analysis of upgrading at the BLF level and blending companies' (changing) sourcing strategies. The analysis of upgrading takes point of departure in product differentiation at the BLF level as an indicator of upgrading and attempts to discern patterns of differences in the BLFs' upgrading strategies. Three dimensions of process upgrading are examined: improvements in the manufacturing process and management of quality, management of supply chain (procurement system), and marketing strategies. Likewise, three dimensions of product upgrading are examined: product consistency, average unit price at auction, price split between fin, and standard quality tea at auction. Finally, recent value-added activities (functional upgrading) are examined.

\section{The "Quality Turn-Around" in the South India Smallholder Tea Sector}

\subsection{Development of the Smallholder-Bought Leaf Factory Strand}

In South India, tea estates date back to the end of the 1800s, where the expansion of plantation-based cultivation of tea was supported by the political and institutional framework of British colonialism [15]. During the 1970s, the government through various support programmes encouraged smallholders to convert from vegetable production for domestic markets to tea cultivation especially for export and round 60,000 smallholder tea growers coexist with large (branded) corporate and medium proprietary tea estates in the Nilgiris (Tamil Nadu). Currently, the privately owned plantation sector comprises both large branded tea manufacturers (e.g., Hindustan Unilever and Tata Tea) with a focus on core competences downstream of the chain-notably branding, packaging and marketing-and smaller, independent (non-branded) tea plantations. Tea exported in packed or bulk form from this sub-sector has historically been excluded from compulsory sale through the auction system in South India [29]. Tea is traded "under the garden name" and mainly directly to the buyers' blending and packing factories in consuming countries, where individual tea grades and qualities are made into consumer blends and packed for domestic sales or re-exported to other countries, for instance, within the European Union. Typically, this strand of the GVC is tightly coordinated in order to comply with specific quality and food safety requirements: the seven tea estates interviewed have only one or a few main buyers (e.g., branded tea manufacturers such as Unilever and Twinings and/or retailers (e.g., Wal-Mart)), relationships tend to be long term, and a majority of the tea grades are sold on forward contracts.

The smallholder-BLF strand originating in South India has been integrated into global tea markets through a loosely coordinated value chain, and the relationships between different agents in the chain tend to be of the "arm's length" kind, while the coordinating mechanism of the chain is based on market principles. The boom period of smallholder-BLF tea production and trade was driven by the demand for low- to medium-quality tea in export markets, notably countries of the former Soviet Union. In the late 1970s, the government of India established bilateral trading agreements with countries of the former Soviet Union. Buoyant global market conditions and a slow phasing out of the bilateral trading agreements after the collapse of the former Soviet Union led to a boom in the South India tea sector in the 1990s, and exports of tea from the Nilgiris continued to increase until the end of the 1990s. From the mid-1970s to the mid-1990s, around 80 per cent of Nilgiri tea production was exported to the former Soviet Union/CIS [30]. At the turn of the century, approximately 65,000 smallholders contributed more than 40 per cent of South India's tea production, with around 75 per cent of the production taking place in the Nilgiris of Tamil Nadu [31,32]. Access to low-interest government loans led to the rapid growth of BLFs, which buy and process green leaves from smallholders. In early 2000s, 156 BLFs were officially engaged in the primary purchasing and processing of tea in the region $[13,33]$. However, by the end of the last decade, around 40 of the 156 BLFs had ceased operating. (As a result of either bankruptcy following the crisis or as a result of closure by the Tea Board of India for failing to 
comply with the minimum health, hygiene and quality requirements stipulated in the Prevention of Food Adulteration Act.)

Trade relations with markets in the CIS countries supported the development of a more or less monopolistic export structure in South India, where Indian tea exporters and producers received relatively high returns for the sale of low-quality bulk tea, when expressed in local currency terms [28] (p. 328). Meanwhile, there was a steady increase in the number of established factories (tea estates and BLFs) converting from orthodox to CTC manufacturing (cut, tear and curl) as a result of the increasing demand for CTC-manufactured tea in export markets, and most of the new BLFs in South India invested in CTC machines. In the orthodox manufacturing process, leaves are rolled against a cutting table and this process retains the aroma of the leaf and (generally) produces high-quality tea. In contrast, in CTC-manufactured tea, leaves are rolled between two rollers and this gives almost twice as high a "cuppage" for the same quantity of tea and a strong liquor and the CTC manufacturing process makes it easier to use lower- to medium-quality teas. (Selective plucking methods are required for the production of orthodox tea (i.e., only two leaves and a bud), while more leaves can be used in CTC tea production because of the cut, tear, curl process.). The major shift from orthodox to CTC production took place between 1980 and 1990, when production of orthodox tea declined from 52 per cent to 24.8 per cent of the total production during the period [34,35]. According to the Tea Board of India and United Planters' Association of Southern India-Krishi Vigyan Kendra (UPASI-KVK) (2005), three decades earlier the smallholder-BLF sector was "known to follow cultural practices, without compromising on quality due to the presence of orthodox tea manufacturing in the region ... However, due to the increasing demand for CTC teas by the erstwhile USSR and other European countries and the favourable market condition for medium teas, quality took a downturn" [35] (p. 5). Smallholders tended to maximise harvest output while BLFs and / or green-leaf buying agents carried out undifferentiated buying of produce from smallholders, and BLFs generally produced low-quality tea based on mature, coarse leaves with a high stalk content [36].

The auctions in South India have historically been the most important channels through which made tea from the smallholder-BLF strand of the chain is distributed to blenders and/or wholesalers. (Though vertically integrated blending companies sourced part of their supplies from their own tea estates and purchased the remainder at the auctions (e.g., Tata Tetley obtained a large proportion of the tea for blending from their own estates in North and South India before they deposed of most of their tea gardens in India)). Apart from functioning as a public price discovery system, the auction system makes available substantial quantities of a range of different grades and qualities (Auctions are conducted on a weekly basis throughout the year in South India, and the auctions in the three auction centres are held on different days of the week.), while brokers (auctioneers) provide an initial assessment of the quality and grade of tea available for sale every week and suggest the expected price rate for different grades and qualities based on market demand and export potential, combined with their own views on the market conditions in India and in international markets. The export reliance of the South Indian tea industry exposed smallholders and BLFs to the vagaries of the world markets. At the end of the 1990s, for example, world tea prices were under pressure: during the three months from February to May 1998, the average price at the Mombassa auction (Kenya) declined by almost 50 per cent, from USD 2.81 per $\mathrm{kg}$ to USD 1.56 per $\mathrm{kg}$ of made tea, with the other auctions experiencing similar drops. However, average tea prices at the three South Indian auctions declined more markedly and more persistently than average tea prices at the other main auctions in the world, suggesting a severe price discount was attached the South Indian tea. In 2003, average tea prices at the South India auctions had declined to well below the cost of production [36].

In response to the severe price crisis and in recognition of changing global market conditions, the executive director of the parastatal Tea Board of India stressed that "the tea factories in the country can no longer sustain domestic and global business without obtaining quality, consistency and process certifications covered by the International Standard Organisation (ISO 9001: 2000), Hazard Analysis and Critical Control Point (HACCP) and the well-known ISI mark from the Bureau of Indian 
standards" [37]. This statement was backed up early in the new millennium, then the Tea Board of India launched a comprehensive "Tea Quality Upgradation and Product Diversification Scheme", and initially allocated 403 crore Rs (USD 93.7 million) to subsidise the costs of upgrading production and processing capacities in the tea sector and improve the competitive position of smallholders and BLFs in the region along with the tea estate sub-sector.

\subsection{Quality Upgrading Interventions Linking Smallholders to Bought Leaf Factories}

The smallholder-BLF sub-sector in South India was specifically targeted via a sub-scheme, "the Quality Upgradation Programme" (QUP), based on collaboration between the Tea Board of India and a regionally based collaboration between the agricultural extension agency (KVK) and UPASI [35]. While the strategy papers do not explicitly refer to value chain interventions, the vocabulary is couched in terms of "product and process upgrading", "value-added activities", "linkage creation between BLFs and farmer groups" and provision of financial assistance to tea gardens (smallholders and tea estates) and factories for renovating production and processing capabilities in order to improve the quality of tea produced and hence "fetch remunerative returns for the tea sold" [33] (p. 1). The programme was initially designed as a five-year initiative and has since been replaced by similar five-year programmes [38]. The QUP targeting the smallholder-BLF strand narrowly concentrated on product and process upgrading: through interventions around the first point of purchase and by subsidising improvements (or new investments) in processing techniques at BLF level the Tea Board of India attempted to circumvent the quality assurance procedures (initiating both product and process upgrading) and encouraging product differentiation and hence potentially increasing the unit value (product upgrading).

A regulatory framework for quality control at the interface between smallholders and BLFs was consolidated. The policy interventions entailed the enforcement of a statutory minimum quality standard and a strengthening of the regulatory and inspection systems at the primary processing and blending levels. Three quality grading standards were identified ("fine", "medium" and "coarse"), based on a common set of leaf indicators for a consignment of tea (Fine standard is defined as two leaves and a bud, medium standard is defined as three leaves and a bud, and coarse standard is defined as more than three leaves and a bud [35]; see also [39] (pp. 64-65)). Tea leaves traded between smallholders and BLFs should be graded according to these standards and premium prices paid for fine-quality tea. Furthermore, the Tea Board of India imposed a minimum quality standard based on the acceptable shoot composition of a consignment of tea: at least 65 per cent of a consignment of tea traded should consist of fine leaves. These regulatory interventions were further strengthened during the late 2000s through a new set of directives specifically related to the enforcement of the minimum quality requirement-the shoot composition of a consignment of tea-attracting penalties in the case of non-compliance.

Organisational and technical improvements at the BLF level (process upgrading) were encouraged through a series of financial incentive structures. The Tea Board of India provided a subsidy of 50 per cent of the total cost of investing in new and/or improved processing techniques (e.g., withering, rolling, drying, fermentation and power handling). On average, 54,000 Rs (USD 1255) have been allocated to 85 BLFs, mainly for financing new and/or improving existing machinery [33]. In addition to financial incentives to upgrade factories, technical assistance and training of well-performing BLFs were provided by UPASI-KVK staff through the QUP (see below). Endorsement of the newly established minimum quality standard was implemented partly through these subsidies, as this entailed signing an "affidavit", confirming that the factories would manufacture tea using only good quality leaves and adhere to the minimum quality standards, whether the material is purchased from smallholders or from tea cultivated on the BLF's own adjacent garden. If they failed to comply, the factories would be obliged to return the subsidy, with interest, to the Tea Board of India.

A second component of the programme entailed the establishment of so-called Quality Tea Procurement and Service Centres organised by women's self-help groups (hereafter SHGs) as a means 
to shorten the value chain and link smallholders directly to the BLFs (Buying agents were accused of "exploiting the growers in the village while procuring leaf from them on behalf of the factories", including cheating on weighing and grading and adding "additionals" to the leaves (water, sand, etc.) before returning to the BLF gate [35] (p. 125)). Most of the women's SHGs had functioned under different NGOs (mostly focusing on empowering women and improving their livelihoods in the villages and with no background in the tea sector) and UPASI-KVK (field and factory officers) played a pivotal role in facilitating the establishment of direct sales arrangements between these newly established quality leaf procurement and service centres and the more progressive BLFs. Seventy quality leaf procurement and service centres were established and registered but, initially, only a few BLFs showed any interest in purchasing from the centres, mainly because the centres were not able to supply sufficient quantities of medium-standard/fine tea leaves. As a result, 20 centres were selected as "model centres" and supplied with leaf procurement sheds, weights and (albeit on a limited scale) fertilisers and pesticides as a means to encourage smallholders to form groups and supply green leaves to these centres on a regular basis. The "SHG-centre model" was aimed at situating responsibility for compliance with the acceptable shoot composition of a consignment of tea at the village/centre level rather than at the factory level: the sorting of tea leaves of different qualities is performed by SHG members at the centres, which in turn provide the BLFs with the possibility of imposing a differential price system based on a price premium attached to fine-quality tea. Further, several "awareness and training meetings" were held in nearly 200 smallholder tea-producing villages in the Nilgiris, with the intention of improving smallholders' plucking practices and increasing the proportion of fine leaf plucked as well as implementing appropriate field maintenance practices. Around one-third of the 110 smallholders interviewed had received training by UPASI-KVK staff (either through in-field training or a half-day meeting organised by UPASI-KVK), and the majority of the growers in the survey were aware that the standard of plucking greatly influences the quality of the made tea.

The move towards value chain interventions for quality upgrading in the South Indian tea sector, targeting both BLFs and smallholders in the region should be well acknowledged. For decades, the industry as a whole encouraged smallholders and BLFs to increase volume rather than quality. Today, however, most smallholders and BLFs are aware of the possible enhancement of product quality through proper husbandry practices in the field and quality management procedures at the factory level. Hence, the "quality upgrading" programme initiated by the Tea Board of India has come a long way in accommodating the trend towards product differentiation and high-quality requirements in mainstream and niche markets (specialty tea) and hence the opportunity to "tap" into these higher-value end-market segments in both national and international markets. It is further worth noting that state interventions and the concomitant upgrading costs to this magnitude run contrary to what has happened in most other traditional cash-crop producing and exporting countries following the implementation of structural adjustment programmes and the withdrawal of the state from key market coordinating functions. According to the Tea Board of India's own estimates, around 35 per cent of the operating BLFs in the region have introduced two or more processing lines, sorting tea leaves of different quality through the production process and providing price-based incentives to smallholders $[35,38]$.

\section{Emerging Bifurcation of the Smallholder-Bought Leaf Factory Strand of the Value Chain?}

As accentuated above, the value chain interventions are premised on incentive structures (financially and training-wise) and diffusion of quality management cum upgrading through the vehicle of "role models". In order to understand what facilitates and enables BLFs to successfully upgrade and what might hinder upgrading, the following subsection explores a group of BLFs that have improved manufacturing practices and started operating in line with the tightly linked smallholder-BLF "model", while another group of BLFs continuing to produce only one (substandard) "tea quality", without any sorting of the leaves before processing, will be considered in the following subsection. In both groups of BLFs, process, product and functional upgrading are examined. 


\subsection{Bought Leaf Factories Moving Up the Quality Ladder in the Nilgiris}

As illustrated in Table 1, ten of the BLFs interviewed during fieldwork in the Nilgiris had recently introduced two or more processing lines, segregating tea leaves of different qualities (fine, medium, and course leaf) through the production process and providing price-based incentives to smallholders. Although with some variation, the BLFs that have initiated product-quality differentiation at the factory level showed a number of similar characteristics and strategies related to process upgrading, which in turn have supported the BLFs in successful product upgrading and, in some cases, functional upgrading into packing and marketing of tea products. These BLFs were strategically approached by the QUP staff because "the BLFs tended to realise above average prices at auction centres and procured fine leaves from smallholders" as emphasized by officials at the Tea Board of India and UPASI-KVK. The average annual production capacity and the capacity utilisation levels of these BLFs were significantly higher than the other sub-group of BLFs, though generally most of the BLFs in the region operated at well below their production capacity.

For the historical reasons alluded to above, none of the BLFs sorted leaves before processing until the serious price downturns in national and international tea markets. The QUP provided the stimulus for important process upgrading at the BLF level by enhancements in the factories' quality-control procedures during the processing of green leaves and their quality procedures at the point of primary purchase through extensive training and technical assistance. These enhancements included inspection of various steps in the processing of made tea (from the withering of green tea to the packing of made tea) related to quality improvement and consistency in the quality of made tea and training of the staff engaged in tea manufacturing and primary purchase. Dual processing lines, where coarser leaves (B grade) are sorted from fine leaves (A grade) and manufactured and packed separately were installed, and six of the factories process two quality products (standard quality and premium quality), while four of the factories process four to six different qualities.

Table 1. Aspects of process upgrading at the BLF level.

\begin{tabular}{|c|c|c|}
\hline & $\begin{array}{l}\text { BLFs with Significant } \\
\text { Elements of Upgrading } \\
(n=10)\end{array}$ & $\begin{array}{l}\text { BLFs without Significant } \\
\text { Elements of Upgrading } \\
\qquad(n=12)\end{array}$ \\
\hline $\begin{array}{l}\text { Quality differentiation } \\
\text { through processing } \\
\text { (frequency) }\end{array}$ & 10 & 0 \\
\hline Capacity (average) million kg & 0.85 & 0.55 \\
\hline $\begin{array}{l}\text { Investment in new or } \\
\text { improved machines } \\
\text { (frequency) }\end{array}$ & 8 & 5 \\
\hline $\begin{array}{l}\text { Adjusted processing } \\
\text { techniques (frequency) }\end{array}$ & 10 & 1 \\
\hline $\begin{array}{l}\text { Quality management of } \\
\text { green-leaf purchase }\end{array}$ & $\begin{array}{l}\text { Outsourced quality assessment to } \\
\text { smallholders and/or SHG centre }\end{array}$ & $\begin{array}{l}\text { Quality assessment (if carried out) by buying } \\
\text { agent and/or at factory level }\end{array}$ \\
\hline $\begin{array}{c}\text { Management of } \\
\text { procurement system }\end{array}$ & $\begin{array}{l}\text { 50-150 smallholders near the BLF } \\
\text { Selected SHG centres }\end{array}$ & $\begin{array}{c}\text { Rely mostly on buying agents } \\
\text { Each agent purchases from 300-500 smallholders }\end{array}$ \\
\hline $\begin{array}{l}\text { Purchasing price: } \\
\text { A: fine } \\
\text { B: medium } \\
\text { C: coarse }\end{array}$ & $\begin{array}{l}\text { A: } 10-12 \mathrm{Rs} / \mathrm{kg} \\
\text { B: } 9-10 \mathrm{Rs} / \mathrm{kg} \\
\text { C: } 7-8 \mathrm{Rs} / \mathrm{kg}\end{array}$ & B-C: 6-8 Rs/kg \\
\hline $\begin{array}{l}\text { Marketing: auction vs. private } \\
\text { sale (average in } \% \text { of total sale) }\end{array}$ & $60 / 40$ & $90 / 10$ \\
\hline
\end{tabular}

These BLFs manufactured on average around 50 per cent of the green-leaf intake based on their own tea cultivation, the remainder being procured from smallholders. In all cases, the BLFs entered the market as an extension of their own tea cultivation activities during the boom period. 
Since then, they had all accumulated a substantial amount of land for tea cultivation. On average, these BLFs had 75 acres and supplemented their own leaf production with the purchase of leaf from smallholders. The introduction of quality differentiation by the BLFs was initially based on the separation of leaves from their own tea cultivation, but this has increasingly been extended to and imposed on the smallholders who supply leaves to the factories. Traditionally, smallholder tea production was a necessary input to the BLFs' production systems, as a means to take advantage of economies of scale and increase processing capacity utilisation at the factories. Buying agents functioned as a key link between the BLFs and smallholders and procurements of tea from the smallholders were based on ad hoc purchases, in other words, when necessary to increase processing capacity utilisation at the factories. In order to increase economies of scale and ensure consistency in the intake of different quality grades, the BLFs modified their procurement system.

Part of this strategy rests on conveying quality requirements to smallholders in order to maintain consistency in the quality of made tea. Staff members of the QUP actively assisted these BLFs in the formation of quality-control teams engaged in monitoring the quality of green leaf prior to manufacturing and enforcement of quality-control procedures at the point of primary purchase. In many cases, the BLFs have either scaled down their purchasing through agents or have stopped using agents altogether and instead tend to focus on fewer growers (between 75 and 150 smallholders), purchasing green leaf directly from the growers through their own buying outlets in villages situated near and around the factories or at the factory gate (see Table 1). The BLFs impose uniform grading procedures at the primary purchase stage in order to assure consistency in the intake of different quality grades as a means to upgrade and differentiate made tea traded at auctions and/or directly to blending companies. The grading system provided quality-inducing price incentives to smallholders to deliver better quality leaf: The BLFs offered 2-3 Rs per kg more for medium-standard tea leaves than for coarser teas in order to obtain a sufficient supply of fine quality, though a few factories offered a substantially higher price premium on fine leaf. In addition, a few of these factories had started purchasing substantial volumes of green leaf from some of the functioning centres run by women's SHGs. For instance, two SHG centres were initially "linked" to one of the factories and, as a result of an increase in the quantity and quality of green leaves supplied by the two centres, the factory increased the number of SHG centres in the area, from which it purchases green leaf, to eight. Not all BLFs however, have increased their reliance on purchasing from the SHG centres, though they were approached by UPASI-KVK staff and it was formally agreed to link one or several centres to the respective factories. As expressed by one of the BLFs, "they [self-help group centres] were not able to provide anything quantity-wise-like $150-200 \mathrm{~kg}$ a day-at the same time we were required to give them a higher rate, so we cancelled the commitment with the centres".

Most (but not all) of these BLFs indicated the economic viability of process upgrading: the restructuring of their procurement system has increased the quality and quantity of green leaf supplied by smallholders, while the cost of monitoring and sorting different qualities at the factory level has considerably reduced. Hence, smallholder tea production has become a necessary input to the product differentiation strategies and product upgrading of these BLFs. Elements of product upgrading is illustrated in Table 2. The consistency in the quality of made tea enables these BLFs to obtain higher unit prices at the auction centre with an average price differential (at the auction centre) between gold tea (very fine-quality, grade A) and standard tea (grade B) of 30 Rs per kg (\$0.66).

In this group of BLFs, there is a general tendency to move away from spot market transactions (partly mediated by buying agents) to direct sourcing strategies (and hence value chain coordination) of green leaf from smallholders and/or the newly established SHG centres in order to ensure a sufficient supply of high(er) quality teas. This tendency is also pronounced in the BLFs' marketing strategies, which reflects blending companies' emphasis on direct sourcing strategies to obtain sufficient volumes of higher quality teas for branded tea products, and the capability of these BLFs to fulfil these requirements. The BLFs increasingly bypass the auction system and secure direct sales arrangements with blenders, packers or wholesalers for domestic consumption or export. (Until 2001, marketing of 
made tea was regulated through the Tea Marketing Control order, which stipulated that 75 per cent of made tea should be sold through the auction system - though this compulsory sale excluded packed tea and bulk tea exports from tea estates [30]. As a result of consistently declining prices at the three auction centres in South India, the Tea Board of India permitted the sale of made tea through any marketing channel from 2001 in order to stimulate price recovery). Direct sales arrangements are more remunerable (i.e., higher margins), though it was not possible to reveal the magnitude of margins measured in higher unit value.

Table 2. Aspects of product and function upgrading at the BLF level.

\begin{tabular}{ccc}
\hline & $\begin{array}{c}\text { BLFs with Significant } \\
\text { Elements of Upgrading } \\
(\boldsymbol{n}=\mathbf{1 0})\end{array}$ & $\begin{array}{c}\text { BLFs without Significant } \\
\text { Elements of Upgrading } \\
(\boldsymbol{n}=\mathbf{1 2})\end{array}$ \\
\hline & Product upgrading & \\
\hline Product consistency & Improved considerably & More or less the same \\
Average unit price at auction (Rs/kg) & 65 & 47.23 \\
Price split between fine/standard tea at auction (Rs) & 30 & None \\
\hline & Functional upgrading & \\
\hline Value-added activities (frequency) & Source: Author's field survey.
\end{tabular}

The factories in this group have remained focused primarily on the upgrading of their existing/conventional businesses (i.e., tea cultivation and manufacturing), but five of the BLFs have recently entered the packaged tea market segment in South India (Table 2). The ability to maintain consistency in the made tea, addressing local and regional preferences in taste combined with the availability of relatively low-cost packing technology have been important factors in the decisions of these BLFs to undertake functional upgrading. In addition, the domestic market for packaged tea in India is rapidly growing and the BLFs sell tea products at the factory's retail outlet (as "single origin tea") and to retailers and specialised tea shops (mainly for tourism) in the region.

\subsection{Bought Leaf Factories Retaining Traditional Manufacturing and Sourcing Practices in the Nilgiris}

The findings summarised in Tables 1 and 2 (below) suggest that there is an emerging bifurcation between BLFs that has convey quality requirements to smallholders as part of their upgrading strategies and BLFs that continue to focus intensively on volume rather than quality. The latter group has relatively low fixed investments and average production capacity and operates at much lower production costs (see also [34]). The strategies of these BLFs were not aimed at producing higher quality made tea. Their manufacturing infrastructure was geared to producing fairly large volumes of standard/substandard made tea and many of the BLFs remain unconvinced that their factories would be economically sustainable if they had to make significant investment in new processing technologies and/or improving existing ones. Although some of these BLFs had also recently made process upgrading-related investments, these investments were mainly aimed at improving the efficiency of the throughput during the processing of made tea. Typical improvements at the factory level were in the form of new/improved dryers, in order to increase the throughput/volume per hour (e.g., from $25 \mathrm{~kg} /$ hour to $75 \mathrm{~kg} /$ hour) and it is generally agreed that these improvements came at a relatively low cost. While this group of BLFs indicated that they had engaged in some form of process upgrading - in particular, improved manufacturing practices-process upgrading in terms of enhanced quality management at primary purchase and product upgrading (producing higher quality made tea) were rare if not absent.

In order to secure sufficient supplies of leaves for operating their factories to full (or sufficient) capacity, it was quite common for these BLFs to rely on buying agents who operated over extremely wide geographical areas. Apart from one BLF, this group of BLFs (and their buying agents) did not impose quality control or grading procedures during primary purchasing in the villages and/or sort coarser and finer leaves before processing. The main focus in transactions between smallholders and 
this group of BLFs remains volume rather than quality, while buying agents working on commission secure a sufficient supply of green leaves by sourcing from 300 to 500 smallholders widely dispersed in the region. As indicated in Table 1, the intensive focus on obtaining economies of scale in low-margin markets is passed on to smallholders in the form of lower buying prices for green leaves, undermining both the credibility of quality control amongst smallholders and the broader reputation of the regional crop.

The geographical diversity in the intrinsic quality of leaves resulting from variable soil, climate and altitude, combined with the lack or limited sorting of leaves before processing makes it tremendously difficult for the BLFs to ensure consistency in the made tea. However, while inconsistency in the product sold by these BLFs might exclude them from certain market segments, low-quality made tea tends to be penalized at the level of price rather than through complete exclusion from the market. Hence, the BLFs maintain access to domestic and export markets regardless of the substandard quality and lack of consistency in the made tea. The sale of made tea takes place primarily through the auction system in the region, the main reason being prompt payment but also, as one of the BLFs interviewed puts it: "Private buyers know we are short [of cash] and that we want to have the money immediately, so they squeeze the prices down".

Branded tea manufacturers and more quality-conscious blending companies (domestic or international) increasingly bypass tea from this segment of the chain at auctions, preferring instead auctioned estate tea or tea originating from the well-known quality-conscious BLFs. A substantial part of the made tea emanating from this segment and traded through auction centres is used either as "filler" in blends or as a substitute for, for example, Kenyan tea to reduce the overall cost of blended tea, or is sold on domestic or export markets as low-value CTC tea. Apparently, emerging markets in for instance the Middle East present new opportunities through which the disposal of substandard tea products can take place. Several Indian-owned companies that were traditionally only engaged in blending and exporting North India high-quality tea (e.g., Darjeeling tea) to markets in Europe have recently invested in blending and warehouse facilities in South India. The decision to start purchasing and exporting auctioned Nilgiris teas was partly based on the availability of "very cheap and fairly good tea suited for export to one dollar markets" (e.g., Pakistan or Iraq)—as expressed by one of the managers interviewed.

\section{Limitations to State-Led Upgrading of the Smallholder-BLF Sector?}

The Tea Board of India and UPASI-KVK have provided the arenas for product and process upgrading in the smallholder-BLF strand of the value chain, against a backdrop of severe price discounts attached to Nilgiris tea and exclusionary dynamics waves in higher-margin markets resulting from the proliferation of product certifications, private proprietary-defined quality and process standards and other types of private governance in retailer- and brand manufacturer-driven strands of the GVC over the last decades. Apart from the enforcement of a statutory minimum quality standard and a uniform grading system differentiated according to the composition of tea leaves, the "upgrading program" provided financial incentive structures and training to BLFs and facilitated linkages between smallholders and BLFs. However, as elucidated above, only around one third of the BLFs have "adopted" the proposed model of upgrading processing techniques and quality control procedures through direct sourcing at the smallholder level as a means to comply with more stringent basic quality criteria and differentiate high quality tea products. Apparently, upgrading trajectories by these BLFs are related to possession of land and processing capacity.

According to the Tea Board of India and the BLFs interviewed, numerous stakeholder meetings organised by the Tea Board of India and UPASI-KVK have been held, where all operating BLFs in the region have in principle agreed to comply with the differentiated grading procedures and to enforce the minimum 65 per cent count of fine leaf at the primary purchasing level. In addition, a consensus on the rejection of substandard quality tea has been formalised: the factories have agreed that if a particular consignment of leaves from a smallholder or buying agent is rejected at one factory due to 
substandard quality, the neighbouring BLFs are obliged to follow suit, thereby forcing the smallholders to improve the quality of tea.

In practice, the picture is much less clear as illustrated above: many BLFs operate at well below their production capacity and follow a strategy of buying leaves from smallholders, regardless of quality, rather than insisting on a minimum quality standard and sorting leaves according to the three grading standards. While repercussions in cases of non-compliance with the minimum quality standards were put in place during the late 2000s, a majority of the BLFs continue to focus on quantity rather quality and at least two observations point towards the limits of state-led upgrading interventions targeting all BLFs in the region: Firstly, according to both officials at the Tea Board of India and the BLFs interviewed, poor-quality made tea can pass the requirements stipulated by the Prevention of Food Adulteration Act (PFA) — even with only 50 per cent of fine leaves. As an official from the Tea Board of India emphasized: "BLFs are aware that, even with far lesser fine leaf than what has been stipulated by the Tea Board, one can make tea which would definitely pass the PFA standard and that the Tea Board would not be in a position to act against them in such cases".

Secondly, as already noted, poor-quality tea may still normally find a market, though in the South Indian case, it has been increasingly harder penalized in terms of price, and the BLFs in the region maintain access to domestic and export markets. This process is fuelled by an increased demand for CTC tea products in emerging markets (notably in the Middle East) and rapidly growing domestic tea consumption-both of which present new opportunities for sale of low-quality CTC teas.

More research is needed to understand the nature and scope of the bifurcation of BLFs as well as its geographical manifestation. However, it remains that the majority of BLFs that have upgraded their processes and products supplement their own tea cultivation with smallholder tea production. These BLFs have strong incentives to engage in vertical coordination and enforcement of effective quality-control procedures in order to reduce the cost of monitoring quality at the factory gate and, at the same time, enjoy greater economies of scale and an optimisation of the benefits of premiums attached to higher quality tea. A majority of these BLFs are concentrated in or near Coonoor Taluk and Kotagiri Taluk, which form the main part of the Nilgiris, characterised by very good infrastructural conditions linking the surrounding villages, while the BLFs that are solely based on purchasing leaves from smallholders are dispersed in more remote areas in the Nilgiris. This seems to suggest emerging regional divergences, where smallholder (and village) access to high(er) value market segments presupposes the "luck" of being intentionally selected by BLFs on the basis of geographical proximity. Thus far, relatively few smallholder communities outside of Coonoor and Kotagiri are involved in any kind of smallholder upgrading initiatives. These smallholders have been the major losers in the face of the changing priorities of branded international and national tea manufacturers in local auctions, who have increasingly bypassed the generally lower quality teas they produce.

\section{Conclusions}

Policy prescriptions on value chain interventions for development, and strategies for moving up the "ladder" in GVCs have proliferated in recent years and are often part of the efforts to improve or strengthen the weakest link in the domestic parts of the value chains and/or to link "smallholders to market programmes" and promote linkages between smallholders and remunerative export markets. Formation of farmers' organisations and direct linkages to the agro-food industry are typically one of the key instruments ([40] (p. 72), [41]). This paper has explored recent state-initiated interventions to upgrade and improve the competitive position of the South Indian smallholder-BLF strand of the GVC for tea. A comprehensive "quality revitalization" scheme financed by the Tea Board of India took the form of enforcing grading standards at the first point of green leaf sale, which was simultaneously intended to resolve crop reputation issues in international markets. In addition, the Tea Board of India provided financial incentive structures, technical assistance and training on a "non-exclusive basis" to BLFs. Apart from "awareness meetings" at the village level focusing on appropriate husbandry practices, the initiated model was based on the premises that product and process upgrading by BLFs 
and direct linkages to smallholders would facilitate more stringent quality requirements transmitted to smallholders.

The research presented in this paper suggests that by directing attention to vertical coordination, competences in quality-control tasks, and catering for compliance with more stringent basic quality criteria, some BLFs have been successful in process, product-and to some extent-functional upgrading. The rewards of quality differentiation are transmitted to smallholders in the form of higher prices attached to higher quality tea leaves. However, the research also suggests that there is an emerging divergence between BLFs operating in line with the tightly linked smallholder-BLF model and those BLFs retaining traditional sourcing practices based on a loosely coordinated supply chain and producing poorer quality teas. The latter group of BLFs did not impose price incentives attached to fine-quality leaves, or grading of leaves at primary purchase, on the grounds that the introduction of grading by any single buyer would simply divert trade to competitors. The loss of volume would severely compromise the profitability of these BLFs, which is based on obtaining economies of scale in low-margin markets. Higher quality standards and vertical coordination seem to result in increasing bifurcation where some smallholder growers are integrated into high-margin markets through prominent BLFs and a mass of "others" outside this tightly coordinated strand of the value chain, supplying low-priced, poor-quality tea mainly traded at the auctions in South India. A different set of upgrading policy strategies that mitigate bifurcation (or in other words exclusion) and uneven economic development would need to take into account the nature of competition and low production capacity utilisation in South India and increasing demand for low-value CTC tea in domestic and export markets. One possible avenue would be to impose higher quality standards and to improve the capacity of the Tea Board of India to enforce and control the quality (and penalize in the case of non-compliance) of the more than 300 registered buying agents and the 118 operating BLFs on a regular basis. However, increasing the capacity of the state to regulate effectively would come at a high price to the public purse and this might call for both private and public sector involvement in the establishment of a strong collective organisation that could create and support initiatives and provide a basis for self-regulation by all BLFs and direct and support the upgrading of smallholder production and offer an inclusive upgrading pathway for the smallholder-BLF strand in the region.

Acknowledgments: This article draws on research conducted in India funded by the Danish Research Council for Society and Business, to which the author most grateful (Grant No. 275-05-0065). Responsibility for the material in the article rests with the author alone.

Conflicts of Interest: The author declares no conflict of interest.

\section{References}

1. Werner, M.; Bair, J.; Fernández, V.R. Linking Up to Development? Global Value Chains and the Making of a Post-Washington Consensus. Dev. Chang. 2014, 45, 1219-1247. [CrossRef]

2. Gereffi, G. Global Value Chains in a Post-Washington Consensus World. Rev. Int. Political Econ. 2013, 21, 9-37. [CrossRef]

3. Lee, J.; Gereffi, G.; Beauvais, J. Global Value Chains and Agrifood Standards: Challenges and Possibilities for Smallholders in Developing Countries. PNAS Early Ed. 2010, 109, 12326-12331. [CrossRef] [PubMed]

4. Fold, N.; Larsen, M.N. Key Concepts and Core Issues in Global Value Chain Analysis. In Globalization and Restructuring of African Commodity Flows; Fold, N., Larsen, M.N., Eds.; The Nordic Africa Institute: Uppsala, Sweden, 2008; pp. 26-43.

5. Gereffi, G. The Organization of Buyer-Driven Global Commodity Chains: How US Retailers Shape Overseas Production Networks. In Commodity Chains and Global Capitalism; Gereffi, G., Korzeniewicz, M., Eds.; Greenwood Press: Westport, New Zealand, 1994; pp. 93-123.

6. Gereffi, G.; Korzeniewicz, M.; Korzeniewicz, R.P. Introduction to “Global Commodity Chains”. In Commodity Chains and Global Capitalism; Gereffi, G., Korzeniewicz, M., Eds.; Greenwood Press: Westport, New Zealand, 1994; pp. 1-15. 
7. Gereffi, G. International Trade and Industrial Up-Grading in the Apparel Commodity Chain. J. Int. Econ. 1999, 48, 37-70. [CrossRef]

8. Humphrey, J.; Schmitz, H. How Does Insertion in Global Value Chains Affect Upgrading in Industrial Clusters? Reg. Stud. 2002, 36, 1017-1027. [CrossRef]

9. Dolan, C.; Humphrey, J. Changing Governance Patterns in the Trade in Fresh Vegetables between Africa and the United Kingdom. Environ. Plan. A 2004, 36, 491-509. [CrossRef]

10. Neilson, J.; Pritchard, B. Value Chain Struggles_Institutions and Governance of the Plantation Districts of South India; Wiley-Blackwell: West Sussex, UK, 2009.

11. Fold, N.; Larsen, M.N. Upgrading in the South's Agro-food Sector: The Role of Lead Firm Strategies and Emerging Country Markets. Int. J. Technol. Learn. Innov. Dev. 2011, 4, 39-66. [CrossRef]

12. Neilson, J. Value Chains, Neoliberalism and Development in Practice: The Indonesian Experience. Rev. Int. Political Econ. 2014, 21, 38-69. [CrossRef]

13. Center for Education and Communication (CEC), FAKT, and Traidcraft. Indian Tea Industry: Market and Value Chain; Centre for Education and Communication: Delhi, India, 2006.

14. Van der Wal, S. Certified Unilever Tea. Small Cup, Big Difference? SOMO: Amsterdam, The Netherlands, 2011.

15. Makita, R. Fair Trade Certification: The Case of Tea Plantation Workers in India. Dev. Policy Rev. 2012, 30, 87-107. [CrossRef]

16. Mitei, Z. Growing Sustainable Tea on Kenyan Smallholder Farms. Int. J. Agric. Sustain. 2011, 9, 59-66. [CrossRef]

17. Gibbon, P.; Ponte, S. Trading Down: Africa, Value Chains \& the Global Economy; Temple University Press: Philadelphia, PA, USA, 2005.

18. Gibbon, P. Commodities, Donors, Value Chain Analysis and Upgrading; Background Paper for the United Nations Conference on Trade and Development (UNCTAD); Danish Institute for International Studies: Copenhagen, Denmark, 2003.

19. Selwyn, B. Institutions, Upgrading and Development: Evidence from North East Brazilian Export Horticulture. Compet. Chang. 2008, 12, 377-396. [CrossRef]

20. Ponte, S.; Ewert, J. Which Way is 'Up' in Upgrading? Trajectories of Change in the Value Chain for South African Wine. World Dev. 2009, 37, 1637-1650. [CrossRef]

21. Mather, C. The Structural and Spatial Implications of Changes in the Regulation of South Africa's Citrus Export Chain. In Globalization and Restructuring of African Commodity Flows; Fold, N., Larsen, M.N., Eds.; The Nordic Africa Institute: Uppsala, Sweden, 2008; pp. 79-102.

22. Larsen, M.N. The International Cotton Market and Cotton Sector Reforms in Sub-Saharan Africa. In Globalization and Restructuring of African Commodity Flows; Fold, N., Larsen, M.N., Eds.; The Nordic Africa Institute: Uppsala, Sweden, 2008; pp. 156-183.

23. Henson, S. New Markets and their Supportive Institutions: Opportunities and Constraints for Demand Growth; Background Paper for the World Development Report 2008; Rimisp-Latin American Center for Rural Development: Santiago, Chile, 2006.

24. Moyer-Lee, J.; Prowse, M. How Traceability Is Restructuring Malawi's Tobacco Industry; Institute of Development Policy and Management: Antwerp, Belgium, 2012; pp. 1-24.

25. Jensen, M. Changing Food Safety Requirements and the Export of Fresh Horticultural Products by Kenyan Smallholders. In Globalization and Restructuring of African Commodity Flows; Fold, N., Larsen, M.N., Eds.; The Nordic Africa Institute: Uppsala, Sweden, 2008; pp. 103-129.

26. Legge, A.; Orchard, J.; Graffham, A.; Greenhalgh, P.; Kleih, U.; Macgregor, J. Mapping Different Supply Chains of Fresh Produce Exports from Africa to the UK. Fresh Perspective-Agrifood Standards and Pro-Poor Growth in Africa. 2008. Available online: http:/ /www.agrifoodstandards (accessed on 25 October 2010).

27. Fold, N.; Gough, K. From Smallholders to Transnationals: The Impact of Changing Consumer Preferences in the EU on Ghana's Pineapple Sector. Geoforum 2008, 39, 1687-1697. [CrossRef]

28. Neilson, J.; Pritchard, B.; Spriggs, J. Implementing Quality and Traceability Initiatives Among Smallholder Tea Producers in South India. ACTA Hortic. 2006, 699, 327-334. [CrossRef]

29. A.F. Ferguson \& Co. Company. Study on Primary Marketing of Tea in India. Summary of Recommendations. Report to the Tea Board of India. Unpublished work, 2002.

30. Ajjan, L.; Raveendran, B. Crisis in Nilgiris Tea Plantations. Plant Horti Tech. 2001, 3, $29-31$. 
31. Tea Board of India. Tea Quality Upgradation and Product Diversification Scheme for the XI Plan Period 2007-2012; Ministry of Commerce and Industries: Kolkata, India, 2007.

32. United Planters' Association of Southern India (UPASI). Plantation Statistics; UPASI: Coonoor, India, 2007.

33. Tea Board of India. Quality Upgradation and Product Diversification Scheme for the Tenth Plan Period 1-9-2003 to 31-3-2007; Ministry of Commerce and Industries: Kolkata, India, 2003.

34. ICRA. The Indian Tea Industry. ICRA Sectoral Analysis; ICTA: Gurgaon, India, 2006. Available online: www.icra.in (accessed on 7 October 2007).

35. Tea Board of India, and UPASI-KVK. Reflections: 5 years of Quality Upgradation Programme in Small Tea Sector in Nilgiris. Status Report: July 2000-July 2005; Tea Board of India and UPASI Krishi Vigyan Kendra: Coonoor, India, 2005.

36. Hayami, Y.; Damodaran, A. Towards an Alternative Agrarian Reform: Tea Plantations in South India. Econ. Political Wkly. 2004, 4, 3992-3997.

37. Sundar, P.S. Global Certification for Tea Factories Gaining Ground. Available online: http://www. thehindubusinessline.com/search/simple.do;jsessionid=6A404F368B5200BF2D345324A62E82CC.stg01 (accessed on 7 October 2007).

38. Government of India. Results-Framework Document for Tea Board (2013-2014); Ministry of Commerce and Industries: Kolkata, India, 2013.

39. Muraleedharan, N.; Hudson, J.B.; Durairaj, J. Guidelines on Tea Culture in South India; United Planters' Association of Southern India: Coonoor, India, 2007.

40. Gibbon, P.; Akyoo, A.; Bolwig, S.; Jones, S.; Lin, Y.; Rants, L.L. An Analysis of Organic Contract Farming in East Africa. In Global Agro-Food Trade and Standards_Challenges for Africa; Gibbon, P., Ponte, S., Lazaro, E., Eds.; Palgrave Machmillan: London, UK, 2010; pp. 70-101.

41. Bolwig, S.; Ponte, S.; du Toit, A.; Riisgaard, L.; Halberg, N. Integrating Poverty and Environmental Concerns into Value Chain Analysis: A Conceptual Framework. Dev. Policy Rev. 2010, 28, 173-194. [CrossRef]

(C) 2016 by the author; licensee MDPI, Basel, Switzerland. This article is an open access article distributed under the terms and conditions of the Creative Commons Attribution (CC-BY) license (http://creativecommons.org/licenses/by/4.0/). 